\title{
Research Paper: Visual Disturbances in Patients With Acute Methanol Poisoning: A Cross-sectional Study.
}

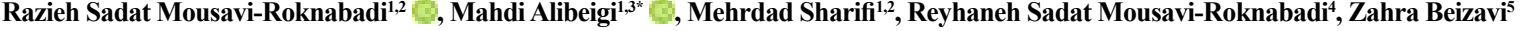

1. Department of Emergency Medicine, School of Medicine, Shiraz University of Medical Sciences, Shiraz, Iran.

2. Emergency Medicine Research Center, Shiraz University of Medical Sciences, Shiraz, Iran.

3.Department of Medical Toxicology, Imam Reza Hospital, Mashhad University of Medical Sciences, Mashhad, Iran.

4.Student Research Committee, Faculty of Medicine, Yazd Branch, Islamic Azad University, Yazd, Iran.

5.Student Research Committee, Department of General Surgery, Faculty of Medicine, Shiraz University of Medical Sciences, Shiraz, Iran.

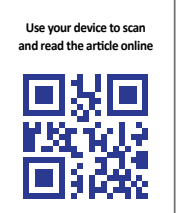

Cttation: Mousavi Roknabadi RS, Alibeigi M, Sharifi M, Mousavi Roknabadi RS, Beizavi Z. Visual Disturbances in Patients With Acute Methanol Poisoning: A Cross-sectional Study. International Journal of Medical Toxicology and Forensic Medicine. 2021; 11(3):33949. https://doi.org/10.32598/ijmtfm.v11i3.33949

https://doi.org/10.32598/ijmtfm.v11i3.33949

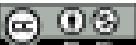

Article info:

Received: 10 Dec 2020

First Revision: 30 Jan 2021

Accepted: 2 Feb 2021

Published: 25 Aug 2021

\section{Keywords:}

Methanol, Poisoning, Epidemiology, Toxicity, Iran

\section{ABSTRACT}

Background: Methanol poisoning is a serious problem in public health, especially in developing countries. The present study aimed to evaluate the incidence of visual disturbances in patients with acute methanol poisoning in the south of Iran.

Methods: This cross-sectional study (from 21/March/2014 to 21/March/2019) was conducted on all adult patients' medical records who were referred to Ali-Asghar Hospital in Shiraz City, Iran, with acute methanol poisoning. The required data were collected using a data-gathering form and were then analyzed.

Results: Twenty male patients were enrolled in this research, with Mean \pm SD age of $33.15 \pm 10.40$ years. Visual disturbances were observed in $15(75 \%)$ of the study subjects, as the most common clinical manifestations. Blurred vision (40\%) and blindness (35\%) were the most frequent visual disturbances in the study participants. None of the study subjects reported photophobia. The explored variables did not differ between patients with visual disturbances and those without visual disturbances. Only one patient who encountered blindness was expired.

Conclusion: The incidence of visual disturbances in the study patients with acute methanol poisoning was higher than that of similar studies. 


\section{Introduction}

ethanol is an alcohol that causes high toxicity among humans; mostly M by direct consumption and rarely through inhalation or skin absorption. As little as $30 \mathrm{~mL}$ of pure methanol can cause permanent blindness and 30-240 mL of it may cause death.

Methanol has little toxicity; however, when metabolized into products, such as formaldehyde and formic acid, it is highly toxic [1]. Methanol poisoning carries high morbidity and mortality, even after hospital discharge [2,3]. Treatment options for methanol poisoning include correcting acidosis, active charcoal, and stomach washing. Hemodialysis is the last treatment option that increases patients' survival and prevents visual damage [2].

Metabolic acidosis, optic nerve neuropathy, and the complications of the central nervous system are the most serious and debilitating consequences of methanol poisoning. Formic acid is the main cause of optic nerve neuropathy [4]. Ophthalmological signs and symptoms of methanol poisoning range from blurred vision and visual field changes to complete blindness. Most patients with methanol poisoning manifest some clinical signs of ophthalmological abnormalities, even in the absence of visual dysfunction [5]. The prevalence of visual disturbances after methanol poisoning ranges from $29 \%$ to $64 \%[1,2,6-8]$.

Methanol poisoning remains a serious problem in developing countries, including Iran, which causes irreversible complications and even death. Alcohol poisoning may be due to suicide; however, in Iran, methanol is considered a cheap and more accessible substitute for ethanol, i.e., resulted in increased methanol poisoning. Based on recently conducted studies, alcohol poisoning is on the rise [2].

This study aimed to evaluate the incidence of visual disturbances in patients with acute methanol poisoning in the south of Iran.

\section{Materials and Methods}

This retrospective cross-sectional study (from 21/ March/2014 to 21/March/2019) evaluated the archived data from all medical records of patients with methanol poisoning who were referred to Ali-Asghar Hospital, affiliated with the Shiraz University of Medical Sciences, and a central Hospital in Shiraz City, Iran, for poisoning patients. The inclusion criteria of the study were patients aged $\geq 16$ years old with methanol poisoning and available medical records in the archives of the hospital. The diagnosis of methanol poisoning was based on the patients' medical history, the level of methanol in blood, or the physician's final diagnosis. Patients with unavailable or incomplete medical files were excluded from the study.

The necessary data were collected using a data-gathering form. This checklist included 3 parts; a. sociodemographic characteristics (e.g., age, gender, marital status, place of residence); b. medical history (e.g., smoking, substance use, alcohol consumption, psychological disorders, \& suicide); c. hospital admission data (e.g., vital at the time of admission, signs and symptoms, laboratory findings, received treatment, $\&$ therapeutic outcomes). Then, the study patients with and without visual disturbances were compared.

All data analyses were performed in SPSS v. 26 using Chi-squared and Fisher's Exact tests for proportions, as well as Independent Samples t-test and Mann-Whitney $\mathrm{U}$ test respecting the mean values. The collected results were presented as Mean \pm SD for continuous variables and summarized in frequency(percentage) for categorical ones. Two-Sided $\mathrm{P}<0.05$ and Confidence Interval (CI) of $95 \%$ were considered to be statistically significant. Furthermore, the missing data were considered in the statistical analysis and recorded as not determined.

The current study was approved by the Vice-Chancellor of Research and Technology, as well as the Ethics Committee of Shiraz University of Medical Sciences (IR.sums.med.rec.1398.150). To observe the ethical issue, the collected data were not revealed to anyone, except for the researchers.

\section{Results}

Totally, 20 medical records were evaluated; all of the explored cases were male, with the Mean $\pm \mathrm{SD}$ age of $33.15 \pm 10.40$ (range: $16-61$ ) years. Moreover, $17(85 \%)$ of them were single and $9(45 \%)$ lived in the urban regions. Besides, $6(30 \%)$ presented a history of smoking, $2(10 \%)$ reported a history of substance dependence, and most of them (70\%) stated no history of psychological disorders. Only 1(5\%) patient who was admitted to the Intensive Care Unit (ICU) was expired. Visual disturbances were detected in $15(75 \%)$ of the research subjects. The Mean \pm SD interval between consumption and arrival to the hospital was $3.13 \pm 2.85$ hours, and the duration of hospitalization was $3.94 \pm 3.98$ days (Table 1). 
Visual disturbances were the most common clinical manifestations (75\%), compared with respiratory and gastrointestinal problems. Furthermore, 10(50\%) study participants reported a history of alcohol consumption. Only one patient who lost vision was expired.

As per Table 2, 7(35\%) patients encountered blindness and $8(40 \%)$ manifested blurred vision. None of the study subjects reported photophobia. In the eye examination, $2(10 \%)$ of the study participants presented miosis and $2(10 \%)$ experienced mydriasis. Additionally, 3(15\%) of the study subjects presented no pupil reactivity. Metabolic acidosis was observed in only $2(10 \%)$ patients. The studied variables did not differ between patients with and without visual disturbances.

\section{Discussion}

The present study data suggested that visual disturbances $(75 \%)$ were the most common clinical manifestations in adult patients with acute methanol poisoning. Totally, $35 \%$ of the examined patients encountered blindness and $40 \%$ had blurred vision.

Hovda et al. reported that $55 \%, 43 \%$, and $41 \%$ of patients presented visual disturbances, gastrointestinal symptoms, and shortness of breath, respectively [3]. Hassanian-Moghaddam et al. studied 25 patients with methanol poisoning and reported that $23 \%$ of them had blindness [6], i.e., lower than the current study findings. Shadnia et al. reported that $64 \%$ of the explored participants experienced visual disturbances [1].

As per Mostafazadeh and Eghbali, 14.3\% of patients encountered visual complications at discharge [7]. Mirzaei et al. reported a prevalence of $39.7 \%$ for vision problems, i.e., mentioned as the most common complication [8]. However, in the study by Massoumi et al., $71 \%$ of the examined patients manifested nausea and vomiting. They reported that blindness was observed in $2 \%$ of the study participants, blurred vision in $41.2 \%$, mydriasis in $27 \%$, and miosis in $2 \%$; similar to the present study, most of the explored patients $(71 \%)$ had a normal pupil size [2].

Sanaei-Zadeh et al. argued that methanol poisoning causes various degrees of visual disturbances; it indicates a significant individual variation in sensitivity to methanol poisoning [9]. Elkhamary et al. evaluated the association between visual and neurological damages in patients with methanol poisoning using MRI images. Optic nerve problems and atrophy were observed in
$56.9 \%$ of patients and bilateral putamen necrosis and visual nerve destruction in $36.2 \%$ of them [10].

In the current study, all patients were male, i.e., consistent with the study by Shadnia and associates [1]. In studies by Mostafazadeh and Eghbali [7] as well as Sanaei-Zadeh et al. [9], 82.1\% and 96\% of the explored patients were male, respectively. Moreover, Hovda et al. [3], Navabi et al. [11], and Massoumi et al. [2] reported that most of the studied patients were male. Therefore, methanol poisoning is more common in men.

The obtained results suggested that the Mean \pm SD of the study subjects' age was $33.15 \pm 10.40$ (range: 16-61) years. Most of the study participants were single, lived in urban areas, had a diploma, and were employed. Furthermore, most of them reported a history of alcohol consumption. However, these factors did not differ between patients with and without visual disturbances. Massoumi et al. declared that $13.7 \%$ of patients were under 20 years of age, $86.3 \%$ lived in urban areas, $11.8 \%$ had a history of suicide, and $13.7 \%$ had a history of substance dependence [2]. Mostafazadeh and Eghbali reported a mean age of 29.3 years in this respect [7]. HassanianMoghaddam et al. reported a mean age of 38.5 years in this regard [6]. Accordingly, methanol poisoning further occurs at younger ages and in urban areas.

This study disregarded specifying the method of methanol consumption; however, Mostafazadeh and Eghbali mentioned drinking as the main method [7]. Additionally, in most cases of the present study, the blood levels of methanol were not recorded. Shadnia et al. reported a median consumption of $20 \mathrm{mg} / \mathrm{dL}$; thus, $37 \%$ of the examined patients consumed $20-50 \mathrm{mg} / \mathrm{dL}$ methanol and $23 \%$ over $50 \mathrm{mg} / \mathrm{dL}$ [1]. Massoumi et al. reported that $74.5 \%$ of patients were intoxicated by industrial alcohol [2].

In the present study, only one patient was admitted to the Intensive Care Unit (ICU), and was expired. This patient was in a coma when admitted to the hospital. Shadnia et al. reported that 8 patients were admitted to the ICU [1]. In the study by Massoumi et al., only $37.3 \%$ of patients were alert when admitted to the hospital [2].

In the present study, there was no difference concerning the blood levels of glucose, potassium, and $\mathrm{pH}$ between the study groups; these factors were not considered as prognostic factors. Shadnia et al. reported that $60 \%$ of patients developed leukocytosis. Moreover, the prevalence of hyperglycemia was reported as $70 \%$, and $40 \%$ of patients manifested hyperkalemia [1]. Sanaei-Zade et al. found a significant correlation between blood glucose 
Table 1. The patients' characteristics

\begin{tabular}{|c|c|c|c|c|c|}
\hline \multicolumn{2}{|c|}{ Variables } & Total & $\begin{array}{l}\text { With Visual Dis- } \\
\text { turbances }(n=15)\end{array}$ & $\begin{array}{c}\text { Without Visual } \\
\text { Disturbances }(n=5)\end{array}$ & $\mathbf{P}$ \\
\hline \multicolumn{2}{|c|}{ Age (y) (Mean $\pm S D)$} & $33.15 \pm 10.4$ & $33.47 \pm 9.92$ & $32.20 \pm 12.76$ & 0.788 \\
\hline \multirow{2}{*}{ Gender No. (\%) } & Men & $20(100)$ & $15(100)$ & $5(100)$ & \\
\hline & Women & $0(0)$ & $0(0)$ & $0(0)$ & - \\
\hline \multirow{3}{*}{ Marital status No. (\%) } & Single & $17(85)$ & $13(86.7)$ & $4(80)$ & \\
\hline & Married & $2(10)$ & $1(6.7)$ & $1(20)$ & 0.468 \\
\hline & Not determined & $1(5)$ & $1(6.7)$ & $0(0)$ & \\
\hline \multirow{3}{*}{ Place of live No. (\%) } & Urban & $9(45)$ & $6(40)$ & $3(60)$ & \\
\hline & Rural & $7(35)$ & $6(40)$ & $1(20)$ & 0.585 \\
\hline & Not determined & $4(20)$ & $3(20)$ & $1(20)$ & \\
\hline \multirow{5}{*}{ Educational level No. (\%) } & Illiterate & $1(5)$ & $1(6.7)$ & $0(0)$ & \\
\hline & Primary & $1(5)$ & $1(6.7)$ & $0(0)$ & \\
\hline & Middle school & $2(10)$ & $2(13.4)$ & $0(0)$ & 0.712 \\
\hline & Diploma & $6(30)$ & $5(33.3)$ & $1(20)$ & \\
\hline & Not determined & $10(50)$ & $6(40)$ & $4(80)$ & \\
\hline \multirow{3}{*}{ Having job No. (\%) } & Yes & $8(40)$ & $8(53.3)$ & $0(0)$ & \\
\hline & No & $1(5)$ & $1(6.7)$ & $0(0)$ & 0.141 \\
\hline & Not determined & $11(55)$ & $6(40)$ & $5(100)$ & \\
\hline \multirow{3}{*}{$\begin{array}{l}\text { Having underlying disease } \\
\text { No. (\%) }\end{array}$} & Yes & $3(15)$ & $3(20)$ & $0(0)$ & \\
\hline & No & $14(70)$ & $10(66.6)$ & $4(80)$ & 0.541 \\
\hline & Not determined & $3(15)$ & $2(13.4)$ & $1(20)$ & \\
\hline \multirow{3}{*}{$\begin{array}{l}\text { History of alcohol consump- } \\
\text { tion }\end{array}$} & No. (\%) & $10(50)$ & $9(60)$ & $1(20)$ & \\
\hline & Yes & $1(5)$ & $0(0)$ & $1(20)$ & 0.182 \\
\hline & $\begin{array}{l}\text { No } \\
\text { Not determined }\end{array}$ & $9(45)$ & $6(40)$ & $3(60)$ & \\
\hline \multirow{3}{*}{ History of smoking No. (\%) } & Yes & $7(35)$ & $6(40)$ & $1(20)$ & \\
\hline & No & $4(20)$ & $2(13.4)$ & $2(40)$ & 0.491 \\
\hline & Not determined & $9(45)$ & $7(46.6)$ & $2(40)$ & \\
\hline \multirow{3}{*}{ History of addiction No. (\%) } & Yes & $2(10)$ & $2(13.4)$ & $0(0)$ & \\
\hline & No & $12(60)$ & $8(53.3)$ & $4(80)$ & 1.0 \\
\hline & Not determined & $6(30)$ & $5(33.3)$ & $1(20)$ & \\
\hline \multirow{3}{*}{$\begin{array}{l}\text { History of psychological } \\
\text { diseases }\end{array}$} & No. (\%) & $1(5)$ & $1(6.7)$ & $0(0)$ & \\
\hline & Yes & $14(70)$ & $11(73.3)$ & $3(60)$ & 1.0 \\
\hline & Not determined & $5(25)$ & $3(20)$ & $2(40)$ & \\
\hline \multirow{3}{*}{ History of suicide No. (\%) } & Yes & $0(0)$ & $0(0)$ & $0(0)$ & \\
\hline & No & $13(65)$ & $10(66.7)$ & $3(60)$ & - \\
\hline & Not determined & $7(35)$ & $5(33.3)$ & $2(40)$ & \\
\hline \multirow{4}{*}{ Transfer to hospital No. (\%) } & By himself & $4(20)$ & $4(26.6)$ & $0(0)$ & \multirow{4}{*}{0.679} \\
\hline & Individual acquaintances & $10(50)$ & $7(46.6)$ & $3(60)$ & \\
\hline & Emergency medical service & $2(10)$ & $2(13.4)$ & $0(0)$ & \\
\hline & Not determined & $4(20)$ & $2(13.4)$ & $2(40)$ & \\
\hline $\begin{array}{l}\text { Duration between consump- } \\
\text { tion }\end{array}$ & $\begin{array}{l}\text { and arrival to the hospital } \\
\text { (hour) (Mean } \pm \text { SD) }\end{array}$ & $3.13 \pm 2.85$ & $3.28 \pm 3.04$ & $2.0 \pm 0.1$ & 0.429 \\
\hline $\begin{array}{l}\text { Duration of hospitalization } \\
\text { (day) }\end{array}$ & $($ Mean $\pm S D)$ & $3.94 \pm 3.98$ & $4.29 \pm 4.61$ & $3.0 \pm 0.71$ & 0.094 \\
\hline \multirow{2}{*}{ Outcome No. (\%) } & Discharged & $19(95)$ & $14(93.3)$ & $5(100)$ & \multirow{2}{*}{1.0} \\
\hline & Death & $1(5)$ & $1(6.7)$ & $0(0)$ & \\
\hline
\end{tabular}


Table 2.. The patients' signs, symptoms, and laboratory data at the time of admission to the hospital

\begin{tabular}{|c|c|c|c|c|c|}
\hline \multicolumn{2}{|c|}{ Variables } & Total & $\begin{array}{l}\text { With Visual } \\
\text { Disturbances } \\
\quad(n=15)\end{array}$ & $\begin{array}{c}\text { Without } \\
\text { Visual Distur- } \\
\text { bances } \\
(n=5)\end{array}$ & $\mathbf{P}$ \\
\hline Vital signs (Mean $\pm S D$ ) & $\begin{array}{c}\text { Systolic blood pressure }(\mathrm{mmHg}) \\
\text { Diastolic blood pressure } \\
\text { (mmHg) } \\
\text { Heart rate }(/ \text { minutes }) \\
\text { Respiratory rate }(/ \text { minutes }) \\
\text { Temperature }\left({ }^{\circ} \mathrm{C}\right) \\
\text { GCS }(/ 15)\end{array}$ & $\begin{array}{c}138.20 \pm 17.16 \\
74.95 \pm 31.41 \\
96.80 \pm 20.28 \\
19.21 \pm 1.51 \\
36.53 \pm 0.86 \\
14.41 \pm 2.65\end{array}$ & $\begin{array}{c}140.20 \pm 18.18 \\
73.40 \pm 34.92 \\
92.60 \pm 17.05 \\
19.13 \pm 1.51 \\
36.52 \pm 0.94 \\
14.15 \pm 3.17\end{array}$ & $\begin{array}{c}132.20 \pm 13.50 \\
79.60 \pm 19.58 \\
109.40 \pm 25.91 \\
19.50 \pm 1.73 \\
36.57 \pm 0.67 \\
15.0 \pm 0.0\end{array}$ & $\begin{array}{l}0.102 \\
0.875 \\
0.783 \\
0.580 \\
0.674 \\
0.357\end{array}$ \\
\hline CNS No. (\%) & $\begin{array}{l}\text { Alert } \\
\text { Coma }\end{array}$ & $\begin{array}{c}19(95) \\
1(5)\end{array}$ & $\begin{array}{c}14(93.3) \\
1(6.7)\end{array}$ & $\begin{array}{c}5(100) \\
0(0)\end{array}$ & 1.0 \\
\hline Ophthalmic No. (\%) & $\begin{array}{l}\text { Blindness } \\
\text { Blurred vision } \\
\text { Photophobia } \\
\text { No symptom }\end{array}$ & $\begin{array}{l}7(35) \\
8(40) \\
0(0) \\
5(25)\end{array}$ & $\begin{array}{c}7(46.6) \\
8(53.3) \\
0(0) \\
0(0)\end{array}$ & $\begin{array}{c}0(0) \\
0(0) \\
0(0) \\
5(100)\end{array}$ & $0<0.001^{*}$ \\
\hline Pupil No. (\%) & $\begin{array}{c}\text { Miosis } \\
\text { Mydriasis } \\
\text { Normal size } \\
\text { Not determined }\end{array}$ & $\begin{array}{l}2(10) \\
2(10) \\
8(40) \\
8(40)\end{array}$ & $\begin{array}{c}1(6.7) \\
2(13.4) \\
8(53.3) \\
4(26.6)\end{array}$ & $\begin{array}{l}1(20) \\
0(0) \\
0(0) \\
4(80)\end{array}$ & 0.090 \\
\hline Pupil reactivity No. (\%) & $\begin{array}{c}\text { Reactive } \\
\text { Not reactive } \\
\text { Not determined }\end{array}$ & $\begin{array}{l}8(40) \\
3(15) \\
9(45)\end{array}$ & $\begin{array}{c}7(46.6) \\
3(20) \\
5(33.3)\end{array}$ & $\begin{array}{c}1(20) \\
0(0) \\
4(80)\end{array}$ & 0.296 \\
\hline Respiratory No. (\%) & $\begin{array}{l}\text { Dyspnea } \\
\text { Depression } \\
\text { No symptom }\end{array}$ & $\begin{array}{c}1(5) \\
1(5) \\
18(90)\end{array}$ & $\begin{array}{c}1(6.7) \\
1(6.7) \\
13(86.7)\end{array}$ & $\begin{array}{c}0(0) \\
0(0) \\
5(100)\end{array}$ & 1.0 \\
\hline Gastrointestinal No. (\%) & $\begin{array}{l}\text { Nausea/vomiting } \\
\text { No symptom }\end{array}$ & $\begin{array}{c}4(20) \\
16(80)\end{array}$ & $\begin{array}{c}4(26.6) \\
11(73.3)\end{array}$ & $\begin{array}{c}0(0) \\
5(100)\end{array}$ & 0.530 \\
\hline Laboratory tests (Mean \pm SD) & $\begin{array}{l}\text { White blood counts } 10^{9 / \mathrm{L}} \\
\text { Lymphocyte } 10^{9 / \mathrm{L}} \\
\text { Blood sugar }(\mathrm{mg} / \mathrm{dL}) \\
\text { Serum sodium (mEq/L) } \\
\text { Serum potassium }(\mathrm{mEq} / \mathrm{L}) \\
\text { BUN (mg/dL) } \\
\text { Creatinine (mg/dL) } \\
\text { PT (Second) } \\
\text { PPT (Second) } \\
\text { INR }\end{array}$ & $\begin{array}{c}9.74 \pm 2.42 \\
20.60 \pm 9.98 \\
114.25 \pm 35.40 \\
137.37 \pm 3.41 \\
4.25 \pm 0.91 \\
11.41 \pm 4.81 \\
1.24 \pm 0.21 \\
14.57 \pm 1.79 \\
29.24 \pm 4.35 \\
1.26 \pm 0.21\end{array}$ & $\begin{array}{c}9.88 \pm 1.91 \\
21.68 \pm 10.42 \\
115.77 \pm 38.25 \\
137.56 \pm 3.10 \\
4.26 \pm 0.94 \\
11.23 \pm 4.99 \\
1.19 \pm 0.19 \\
14.21 \pm 1.77 \\
28.85 \pm 4.38 \\
1.22 \pm 0.19\end{array}$ & $\begin{array}{c}9.28 \pm 4.15 \\
17.08 \pm 8.66 \\
107.67 \pm 23.18 \\
136.75 \pm 4.79 \\
4.20 \pm 0.95 \\
12.0 \pm 4.83 \\
1.40 \pm 0.23 \\
15.75 \pm 1.50 \\
30.50 \pm 4.65 \\
1.37 \pm 0.25\end{array}$ & $\begin{array}{l}0.118 \\
0.796 \\
0.981 \\
0.928 \\
0.515 \\
0.836 \\
0.247 \\
0.211 \\
0.584 \\
0.058\end{array}$ \\
\hline Vein blood gas & $\begin{array}{c}\mathrm{PH}(\text { Mean } \pm \mathrm{SD}) \\
\mathrm{PCO}_{2}(\text { Mean } \pm \mathrm{SD}) \\
\mathrm{HCO}_{3}(\text { Mean } \pm \mathrm{SD}) \\
\left.\mathrm{O}_{2} \text { saturation (Mean } \pm \mathrm{SD}\right) \\
\text { Metabolic acidosis No. (\%) } \\
\text { Respiratory alkalosis No. (\%) }\end{array}$ & $\begin{array}{c}7.23 \pm 0.11 \\
26.73 \pm 9.41 \\
21.40 \pm 39.30 \\
90.27 \pm 22.72 \\
2(10) \\
1(5)\end{array}$ & $\begin{array}{c}7.23 \pm 0.10 \\
28.14 \pm 10.17 \\
24.95 \pm 44.69 \\
88.36 \pm 26.53 \\
2(13.4) \\
1(6.7)\end{array}$ & $\begin{array}{c}7.25 \pm 0.15 \\
22.15 \pm 4.71 \\
9.88 \pm 4.09 \\
95.50 \pm 3.70 \\
0(0) \\
0(0)\end{array}$ & $\begin{array}{c}0.215 \\
0.432 \\
0.466 \\
0.432 \\
1.0 \\
1.0\end{array}$ \\
\hline Treatment No. (\%) & $\begin{array}{l}\text { Gastric lavage } \\
\text { Active charcoal } \\
\text { Hemodialysis } \\
\text { Sodium bicarbonate } \\
\text { Folic acid folinate } \\
\text { Fompizol }\end{array}$ & $\begin{array}{c}0(0) \\
1(5) \\
17(85) \\
12(60) \\
16(80) \\
0(0)\end{array}$ & $\begin{array}{c}0(0) \\
1(6.7) \\
12(80) \\
10(66.7) \\
12(80) \\
0(0)\end{array}$ & $\begin{array}{c}0(0) \\
0(0) \\
5(100) \\
2(40) \\
4(80) \\
0(0)\end{array}$ & $\begin{array}{c}- \\
1.0 \\
0.539 \\
0.347 \\
1.0 \\
-\end{array}$ \\
\hline Number of hemod & alysis (Mean $\pm S D$ ) & $1.45 \pm 0.94$ & $1.40 \pm 1.06$ & $1.60 \pm 0.55$ & 0.492 \\
\hline $\begin{array}{l}\text { The time interval between arrival } \\
\text { to the hospital and first hemodi }\end{array}$ & Alysis (hour) (Mean $\pm S D$ ) & $5.46 \pm 2.0$ & $5.25 \pm 1.84$ & $6.08 \pm 2.62$ & 0.163 \\
\hline
\end{tabular}

SD: standard deviation; GCS: Glasgow Coma Scale; CNS: Central Nervous System; BUN: Blood urea nitrogen; PT: Prothrombin Time; PTT:Partial thromboplastin time; INR:The international normalized ratio. 
levels and $\mathrm{pH}$ and base deficit; however, no correlation was found between blood glucose levels and the duration of treatment, age, or serum bicarbonate concentration. Finally, they concluded that hyperglycemia can be a new prognostic factor in patients with methanol poisoning; however, further studies are required in this respect [9].

Desai et al. addressed $\mathrm{pH}$ as the strongest predictor for final visual acuity and its improvement. The risk of transient visual impairment is high in patients with a $\mathrm{pH}<7.2$ [5]. Ma et al. found that, at the initial stages of acute poisoning, all patients presented transient systemic symptoms (the vision ability of 0.1 or even less). After receiving treatment, the study patients' visual function was improved to different degrees at the one-year follow-up, but it was not satisfactory [12]. However, Shadnia et al. and Hassanian-Moghaddam et al. reported a similar level of $\mathrm{pH}$ between those who expired and those who survived $[1,6]$. In line with the results of this study, Sanaei-Zadeh et al. reported no difference concerning $\mathrm{pH}$ concentration and the time interval between consumption and arrival to the hospital between the patients with and without visual disturbances [9].

The mortality rate was measured as $5 \%$ in our study; however, Shadnia et al. [1] and Sanaei-Zadeh et al. [9] reported mortality rates of $30 \%$ and $28 \%$, respectively. Hassanian-Moghaddam et al. reported a mortality rate of $48 \% ; 77 \%$ of them were fully recovered without any complications. For patients with a comma, the mortality rate was reported as $90 \%$; while for other patients, it was reported as $20 \%$, and this difference was statistically significant [6]. Mostafazadeh and Eghbali stated that approximately $18 \%$ of patients died in hospitals despite receiving appropriate treatment [7]. In the study by Massoumi et al., 4 patients died, also 15 patients with complications and 32 without complications, were survived [2].

In the study by Hovda et al., 8/59 patients with definite methanol poisoning died out of the hospital, and 9/59 died inside the hospital [3]. Ten percent of patients with the sequel and $73 \%$ without sequel survived. The authors reported that late hospital admission is the main cause of high morbidity and mortality. Prognostic factors for poor outcomes included respiratory arrest, coma, and severe metabolic acidosis at the time of admission. Finally, they argued that rapid admission, respiratory compensation, and metabolic acidosis were associated with patients' survival [3]. Paasma et al. identified $\mathrm{pH}<7$, coma [Glasgow Coma Scale (GCS) <8)], and insufficient hyperventilation at the time of hospital admission, as the strong predictors of the final therapeutic outcomes [13].
Shadnia et al. found that coma, respiratory depression, $\mathrm{PaCO}_{2}$, and hyperglycemia were strong prognostic factors for undesirable survival in these patients [1]. Furthermore, Hassanian-Moghaddam concluded that $\mathrm{pH}<7$ and coma at the time of admission, as well as delayed hospital admission ( $>24$ hours), are associated with a poor prognosis [6].

In this study, Computed Tomography (CT) scan findings of all patients were not recorded; thus, their exact investigation was impossible. However, Taheri et al. declared that $66.6 \%$ of patients with acute methanol poisoning manifested abnormal brain CT scan findings. They stated that in addition to clinical and laboratory findings, the presence of putamen hemorrhage and subcortex white matter necrosis, i.e., detectable in the brain CT scans of patients with acute methanol poisoning, are associated with poor outcomes. Therefore, this modality can be useful for physicians [14]. Sefidbakht et al. stated that CT scans and MRI data reveal changes in patients with methanol poisoning which can be helpful for physicians [15].

There was no significant difference between the research groups concerning the provided treatment. Shadnia et al. reported that treatment methods provided to both patients who either expired or survived were statistically the same. Besides, the treatment type did not affect the prognosis of patients [1]. Moghadami et al. found that folinic acid infusion provided no protective effect and only reduced acidosis in patients receiving folate [16] Massoumi et al. recommended the rapid use of sodium bicarbonate in patients with methanol poisoning [2].

In developing countries, identifying methanol poisoning has limitations. Thus, active case finding and developing guidelines are beneficial interventions for reducing morbidity and mortality induced by methanol poisoning [17]. Increasing population' and healthcare providers' awareness about the complications of methanol poisoning and their prevention methods would be useful. Early diagnosis and treatment can prevent long-term complications. Additionally, the time interval between methanol intake and hospital admission is critical for preventing complications and death [2].

This was a retrospective study; accordingly, not recording methanol poisoning in the patients' medical records was expected to be a major problem, i.e., also found during the study. Most of the examined cases were recorded as alcohol poisoning; therefore, methanol poisoning was identified through evaluating the medical history sheets or physicians' notes. Thus, the speed of data collection was very slow. Meanwhile, several patients' medical 
records may have been missed. Furthermore, the limited number of investigated patients per year, the high frequency of incomplete records, and the inadequacy of data were among the main limitations, which may have influenced the prognostic factors. Additionally, the low number of identified patients in the present study can be because some patients with methanol poisoning are referred to other centers. Therefore, multicenter, prospective studies can provide more precise information for physicians and policymakers. Establishing a registry system for patients with poisoning can provide further data in this regard.

\section{Conclusion}

In the present study, the incidence of visual disturbances in patients with acute methanol poisoning was higher than that in similar studies. Healthcare managers and policymakers should pay more attention to preventing methanol poisoning.

\section{Ethical Considerations}

\section{Compliance with ethical guidelines}

The current study was approved by the Vice-Chancellor of Research and Technology, as well as the Ethics Committee of Shiraz University of Medical Sciences (IR.sums.med.rec.1398.150). To observe the ethical issue, the collected data were not revealed to anyone, except for the researchers.

\section{Funding}

The current study was financially supported by the Vice-Chancellor of Research and Technology of Shiraz University of Medical Sciences (Grant No.: 19165).

\section{Author's contributions}

Study concept and design: Razieh Sadat MousaviRoknabadi, Mahdi Alibeigi, Mehrdad Sharifi; Searching the related articles: Razieh Sadat Mousavi-Roknabadi, Zahra Beizavi; Data collection: Mahdi Alibeigi; Data analysis: Razieh Sadat Mousavi-Roknabadi, Reyhaneh Sadat Mousavi-Roknabadi; Drafting of the manuscript: Razieh Sadat Mousavi-Roknabadi, Mahdi Alibeigi, Mehrdad Sharifi, Reyhaneh Sadat Mousavi-Roknabadi, Zahra Beizavi; Critical revision of the manuscript for important intellectual content: Razieh Sadat MousaviRoknabadi, Mahdi Alibeigi, Mehrdad Sharifi, Reyhaneh Sadat Mousavi-Roknabadi, Zahra Beizavi; Final confirmation: Razieh Sadat Mousavi-Roknabadi, Mahdi
Alibeigi, Mehrdad Sharifi, Reyhaneh Sadat MousaviRoknabadi, Zahra Beizavi.

\section{Conflict of interest}

The authors declared no conflicts of interest.

\section{Acknowledgments}

The authors thank Ms. Negar Gheibi for her assistance in data gathering.

\section{References}

[1] Shadnia S, Rahimi M, Soltaninejad K, Nilli A. Role of clinical and paraclinical manifestations of methanol poisoning in outcome prediction. J Res Med Sci. 2013; 18(10):865-9. [PMCID]

[2] Massoumi G, Saberi K, Eizadi-Mood N, Shamsi M, Alavi M, Morteza A. Methanol poisoning in Iran, from 2000 to 2009. Drug Chem Toxicol. 2012; 35(3):330-3. [DOI:10.3109/0148054 5.2011.619193] [PMID]

[3] Hovda KE, Hunderi OH, Tafjord AB, Dunlop O, Rudberg N Jacobsen D. Methanol outbreak in Norway 2002-2004: Epidemiology, clinical features and prognostic signs. J Intern Med. 2005; 258(2):181-90. [DOI:10.1111/j.1365-2796.2005.01521.x] [PMID]

[4] Pakravan M, Esfandiari H, Sanjari N, Ghahari E, Hassanpour K. [Additive effect of erythropoietin on conventional treatment of methanol induced toxic optic neuropathy (Persian)]. Bina J Ophthalmol. 2017; 22(3):218-25. http:/ / binajournal.org/article-1-878-en.html

[5] Desai T, Sudhalkar A, Vyas U, Khamar B. Methanol poisoning: Predictors of visual outcomes. JAMA Ophthalmol. 2013 131(3):358-64. [DOI:10.1001/jamaophthalmol.2013.1463] [PMID]

[6] Hassanian-Moghaddam H, Pajoumand A, Dadgar SM, Shadnia Sh. Prognostic factors in methanol poisoning. Hum Exp Toxicol. 2007; 26(7):583-6. [DOI:10.1177/0960327106080077] [PMID]

[7] Mostafazadeh B, Eghbali H. An epidemiologic study on methyl alcohol poisoning in Tehran, Iran. Asia Pac J Med Toxicol. 2014; 3(S 1):8. [DOI:10.22038/apjmt.2014.2879].

[8] Mirzaee V, Riahi Z, Sharifzadeh Z, Parizi MK, Adinehpour A. Survey on methanol poisoning epidemic in Rafsanjan city in year 2013. Intern Med Med Invest J. 2017; 2(3):84-9. [DOI:10.24200/imminv.v2i3.47]

[9] Sanaei-Zadeh H, Esfeh SK, Zamani N, Jamshidi F, Shadnia S. Hyperglycemia is a strong prognostic factor of lethality in methanol poisoning. J Med Toxicol. 2011; 7(3):189-94. [DOI:10.1007/s13181-011-0142-x] [PMID] [PMCID]

[10] Elkhamary SM, Fahmy DM, Galvez-Ruiz A, Asghar N, Bosley TM. Spectrum of MRI findings in 58 patients with methanol intoxication: Long-term visual and neurological correlation. Egypt J Radiol Nucl Med. 2016; 47(3):1049-55. [DOI:10.1016/j.ejrnm.2016.06.011] 
[11] Navabi SJ, Eivazi M, Beiranvand B. [An epidemiological study of patients with methanol poisoning and the factors affecting the prognosis of patients in Imam Khomeini hospital Kermanshah 2010-2015 (Persian)]. Sci J Forensic Med. 2018; 24(3):175-84. http://sjfm.ir/article-1-793-en.html

[12] Ma Z, Jiang $H$, Wang J. Clinical analysis of severe visual loss caused by inhalational methanol poisoning in a chronic process with acute onset: A retrospective clinical analysis. BMC Ophthalmol. 2019; 19(1):124. [DOI:10.1186/s12886-0191127-9] [PMID] [PMCID]

[13] Paasma R, Hovda KE, Hassanian-Moghaddam H, Brahmi N, Afshari R, Sandvik L, et al. Risk factors related to poor outcome after methanol poisoning and the relation between outcome and antidotes: A multicenter study. Clin Toxicol (Phila). 2012; 50(9):823-31. [DOI:10.3109/15563650.2012.728224] [PMID]

[14] Taheri MS, Moghaddam HH, Moharamzad Y, Dadgari $\mathrm{S}$, Nahvi V. The value of brain CT findings in acute methanol toxicity. Eur J Radiol. 2010; 73(2):211-4. [DOI:10.1016/j. ejrad.2008.11.006] [PMID]

[15] Sefidbakht S, Rasekhi AR, Kamali K, Borhani Haghighi A, Salooti A, Meshksar A, et al. Methanol poisoning: Acute MR and CT findings in nine patients. Neuroradiology. 2007; 49(5):427-35. [DOI:10.1007/s00234-007-0210-8] [PMID]

[16] Moghadami M, Masoumpoor M, Tabei SM, Tabaei SM, Sadeghi H, Gholami K, et al. Therapeutic response to Folinic acid in methanol poisoning epidemic in Shiraz. Iran J Med Sci. 2015; 33(1):22-6. https://ijms.sums.ac.ir/article_39813.html

[17] Hassanian-Moghaddam H, Zamani N, Rahimi M, Shadnia S, Pajoumand A, Sarjami S. Acute adult and adolescent poisoning in Tehran, Iran; The epidemiologic trend between 2006 and 2011. Arch Iran Med. 2014; 17(8):534-8. [DOI: 014178/ AIM.003] 